\title{
Oxygen in Complex Oxide Thin Films Grown by Pulsed Laser Deposition: a Perspective
}

\author{
Gertjan Koster $^{1}$ (D) Dave H. A. Blank ${ }^{1}$ - Guus A. J. H. M. Rijnders ${ }^{1}$
}

Received: 9 August 2019 / Accepted: 28 August 2019 / Published online: 16 October 2019

(C) The Author(s) 2019

\begin{abstract}
For thin film synthesis of complex oxides, one of the most important issues has always been how to oxidise the material. For a technique like pulsed laser deposition, a key benefit is the relatively high oxygen background pressure one can operate at, and therefor oxidation should be relatively straightforward. However, understanding the microscopic oxidation mechanisms turns out to be rather difficult. In this perspective, we give a brief overview of the sources of oxidation for complex oxide thin films grown by pulsed laser deposition. While it is clear what these sources are, their role in the kinetics of the formation of the crystal structure and oxygen stoichiometry is not fully understood.
\end{abstract}

Keywords Complex oxides $\cdot$ Thin films $\cdot$ Pulsed laser deposition $\cdot$ Oxidation $\cdot$ High Tc superconductors

\section{Introduction}

The role of pulsed laser deposition for (superconducting) oxides became of significance with the announcement by the Venkatesan group in mid-1987 [1] that they were able to grow thin layers of the early-1987 discovered by Chu et al. [2] high Tc material $\mathrm{YBa}_{2} \mathrm{Cu}_{3} \mathrm{O}_{7-\mathrm{d}}$ (YBCO). In the seminal paper by Dijkkamp et al., it was recognised that with the technique pulsed excimer laser evaporation (now commonly known as pulsed laser deposition while other terms are also used in literature: laser sputtering, laser-assisted deposition and annealing, pulsed laser evaporation, laser molecular beam epitaxy, laser-induced flash evaporation, laser ablation, etc. [3]), superconducting films were produced of this material. More importantly, they have shown that the complex ('123') stoichiometry of the target material was retained in the thin layer, as was measured by RBS. To quote the authors: 'As to the mechanism of the deposition, we feel that the similarity in stoichiometry between the bulk material and the deposit is due to the highly nonequilibrium nature of pulsed laser heating'... '...material is most likely ejected in the form of

Gertjan Koster

g.koster@utwente.nl

1 Universiteit Twente Enschede, Enschede, Netherlands fairly large molecular clusters, which may explain the preservation of the stoichiometry in the deposited film, in particular the high oxygen content'. In the years that followed, a lot of attention was paid to the nature of the laser-target interaction and the influence of the laser parameters on the quality of the thin films. For example, in the table taken from Norton et al. [4], it can be seen how the different parameter settings were prioritised in terms of their role in the formation of an epitaxial, crystalline film (Table 1).

To better understand the 'miracle' of stoichiometry in PLD, the modelling and experimental study of plasmas have taken a prominent role very early on, revealing a transient and highly complex mixture of constituents, ranging from atoms, ions, molecules and larger clusters [5]. Of particular interest to most researchers has always been the cation stoichiometry arriving at the substrate surface (and with the relative angle to the laser focal point), both as a function of ablation parameters that were used as well as the exact pressure and composition of the background gas. Some noteworthy examples from literature are studies on the laser-target interaction in relation to the stoichiometry of the thin film [6-9] on plasma dynamics [10-21] or in particular the effect of substrate heating on the plasma heating [22-24]. For complete reviews on the PLD technique, recommended texts are given in [25-27]. From these studies, it is clear that both the background gas used and its pressure play a prominent role in the temporal development of the plasma plume as well as the oxidation of the film material. 
Table 1 Relationship between processing parameters and the microstructure development in thin films

\begin{tabular}{llll}
\hline Category & Parameters & Effect on process & Possible effects on microstructure \\
\hline Primary & $\begin{array}{l}\text { Laser wavelength } \\
\text { Laser power density } \\
\text { Laser pulse repetition rate }\end{array}$ & $\begin{array}{l}\text { Thermal or non-thermal evaporation } \\
\text { Ratio of neutral to ionic species in the plasma }\end{array}$ & $\begin{array}{l}\text { Retention of target stoichiometry } \\
\text { Formation of metastable microstructures Particulates }\end{array}$ \\
Secondary & $\begin{array}{l}\text { Substrate temperature } \\
\text { Oxygen partial pressure }\end{array}$ & $\begin{array}{l}\text { Kinetic energy of ejected species } \\
\text { Surface mobility of ablated species }\end{array}$ & $\begin{array}{l}\text { Formation of metastable microstructures } \\
\text { Establishment of epitaxy } \\
\text { Tertiary }\end{array}$ \\
& Substrate-pellet distance & Film thickness & Control of crystal structure (orthorhombictetragonal) \\
& Irradiated spot size & Thickness distribution across substrate & Not known
\end{tabular}

Taken from [4] with permission

Next to the study of the typical PLD parameters, in situ monitoring of the growth kinetics has also led to various models on the surface kinetics, mostly based or derived from existing models developed for metals and 'standard' semiconductors. While we refrain from an in-depth discussion here and refer to existing literature [e.g. 28-30], we would like to emphasise that PLD is characterised by a very high 'instantaneous' deposition rate due the inherently pulsed nature of deposition. That leads to very high nucleation rates and typically high step densities, which results in high growth rate just after the deposition pulse, a feature that sometimes can be exploited when dealing with species of high volatility. However, a complete picture of the oxidation chemistry inside the plasma and the role of the surface chemistry has been largely ignored to date. For example, the effect of oxidation and termination on diffusivity cannot be explained by the existing models.

In this perspective, we will give a brief overview of the current state of knowledge on the origins of oxygen in complex oxide thin films grown by PLD (possibly relevant for other methods as well) and an outlook for the coming years on. We will not be able to answer all the above questions but instead we will highlight the important clues from experiment to stimulate the development of new models and experiments.

\section{Origin of Oxygen in Complex Oxides Grown by PLD}

\subsection{Some Historical Notes}

Interestingly, going back to the Dijkkamp paper [1], the authors described that the first YBCO films were grown in a background pressure of about $10^{-7}$ mTorr with the substrate kept at $450{ }^{\circ} \mathrm{C}$. These films required a post-annealing step to obtain superconductivity (see left panel of Fig. 1 for the resulting conduction properties of the films obtained this way).

Approximately 1 year later, researchers reported fully epitaxial superconducting thin films (see middle panel of Fig. 1), grown at much higher temperature $\left(>700^{\circ} \mathrm{C}\right)$, using a much higher oxygen background pressure in the range of $0.1-$ 0.3 mbar [31] resulting in nearly perfect (super)conducting YBCO thin films [32]. The reported increase in (oxygen) pressure marked another important step in the synthesis of oxide thin films, as none of the other existing physical vapour techniques operated at such conditions (often activated forms of oxygen have to be introduced, such as ozone or atomic oxygen $[33,34])$. The authors claimed at the time the PLD technique to be a true 'one step' procedure, whereas in reality, it was known that the superconducting phase would only form upon cooling while increasing the oxygen background to
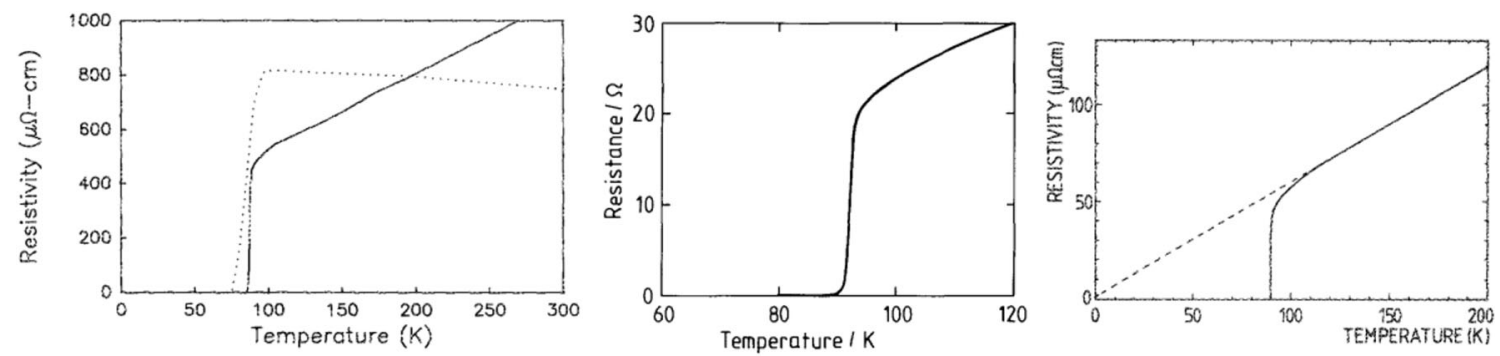

Fig. 1 (left panel) Four-point probe resistance vs temperature measurements for two films of approximately 300-nm thickness, annealed as described in the text. (Solid line) On a (100) $\mathrm{SrTiO}_{3}$ substrate; (dotted line) on $\mathrm{Al}_{2} \mathrm{O}_{3}$ with resistivity in arbitrary units, following a two-step process, taken from [1] with permission; (middle panel) temperature dependence of the resistance of an $\mathrm{YBa}_{2} \mathrm{Cu}_{3} 0_{7-\mathrm{d}}$ film on (001)- $\mathrm{SrTi}_{3}$ grown at higher oxygen partial pressures, taken from [31] with permission; (right) resistivity vs temperature plot of an early $\mathrm{YBa}_{2} \mathrm{Cu}_{3} 0_{7-\mathrm{d}}$ thin film at fully optimised PLD conditions, taken from [32] with permission 
Fig. 2 Photograph of the laserinduced $\mathrm{La}_{0.6} \mathrm{Sr}_{0.4} \mathrm{MnO}_{3}$ plasmas in vacuum at various $\mathrm{pO}_{2}$ [36].with permission
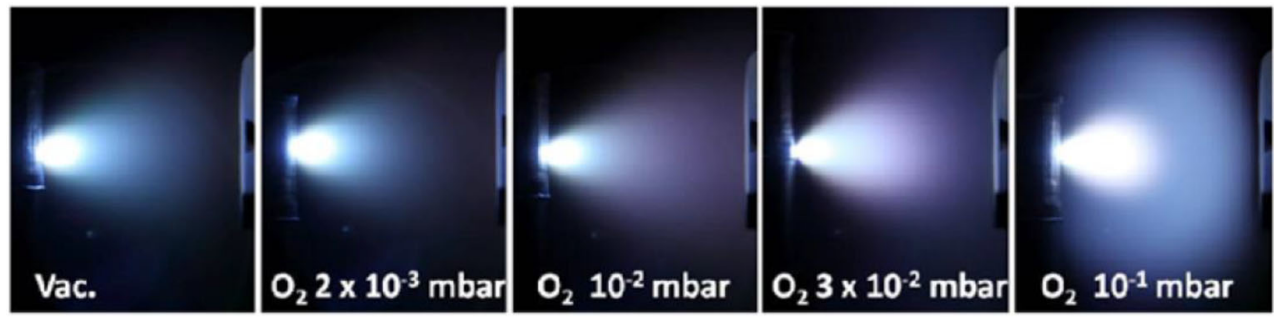

several 100 mbar. In terms of crystallisation, it was shown that using the PLD technique, one could form complex oxides over a large range of oxidation conditions (see also discussion below).

\subsection{Three Sources of Oxygen}

In principle, one can distinguish three sources of oxygen during PLD: background by an oxidising gas such as $\mathrm{O}_{2}, \mathrm{NO}_{2}$ or ozone (provided that the base pressure of the vacuum system is sufficiently low), target/plasma and substrate. As was early on recognised and also remarked above, for PLD, there is no real upper limit to the background pressure that can be used. Yet, it must be said that as a vapour phase deposition technique, 1 mbar is roughly the practical boundary above which significant nucleation of larger particulates occurs [35] in the 'plasma' that expands towards a substrate and cools, a feature that nowadays is used as a nanoparticle synthesis technique. Therefore, a deposition can typically take place over 6 orders of magnitude of oxygen partial pressure, which is a true benefit when growing complex oxides consisting of various (transition metal) elements with different affinities for oxidation.

Chen et al. determined quite elegantly by ${ }^{18} \mathrm{O}$ experiments whether oxygen in the film originates from the background or somewhere else, as a function of background pressure [36].
As one would expect, oxygen from the background became increasingly prominent in the films with increasing background pressure. This is both an effect of the increased interaction (collisions) of the ejected atoms and molecules (see Fig. 2 as an illustration of the visible changes of the plasma plume as a function of background pressure), as well as an enhanced direct exchange of the background oxygen with the grown layer.

Regarding the plasma/target as a separate source of oxygen, in 1998, it was shown by Lopez et al. that if immediately (within a few seconds) after growing YBCO at standard conditions the film would be quenched, superconductivity was still measured $[37,38]$. In Fig. 3, $\mathrm{T}_{\mathrm{c}, 0}$ is plotted as a function of substrate-to-target distance. Also, the oxygen pressure during growth was varied. $\mathrm{T}_{\mathrm{c}, 0} \mathrm{~s}$ up to $50 \mathrm{~K}$ were observed whereas films that were allowed to equilibrate to room temperature at a fixed background pressure were semiconducting, as expected. The authors conclude that activated (atomic) oxygen must have been present during deposition, which is known to have a much higher effective oxidation power compared to molecular oxygen. Both the target as well as the collisions in the plasma plume could be sources of this activated oxygen.

Furthermore, several experiments pointed to the substrate as a source of oxygen, in particular when the
Fig. 3 Critical temperature $(R=$ $0)$ of quenched films as a function of the target substrate distance for different oxygen pressures, taken from [37] with permission

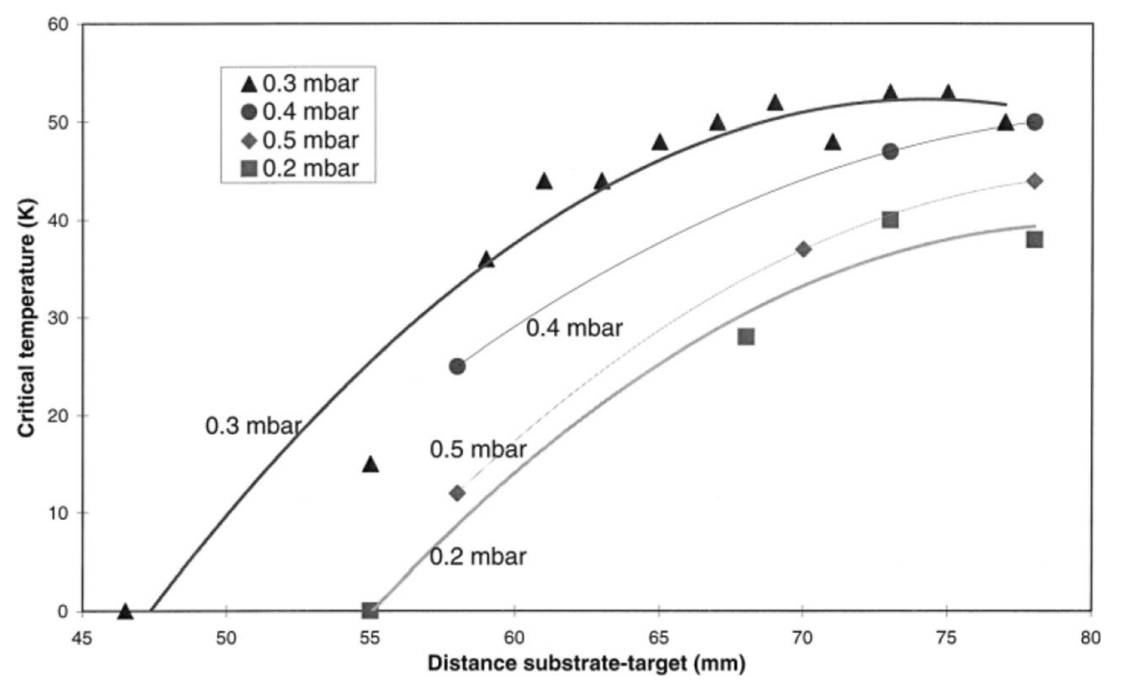



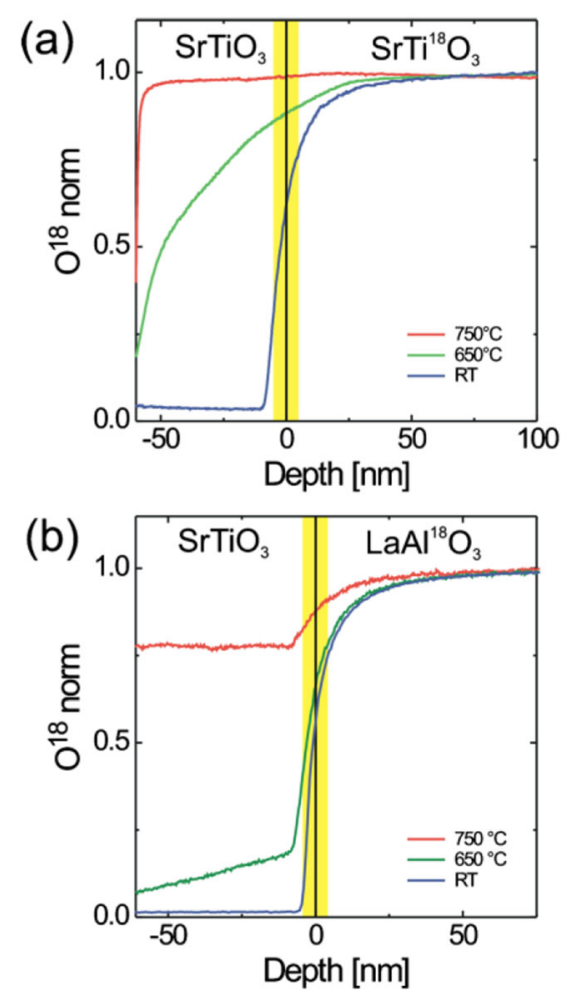

Fig. 4 a ${ }^{18} \mathrm{O}$ SIMS depth profile of $\mathrm{SrTiO}_{3}$ on $\mathrm{SrTi}^{18} \mathrm{O}_{3}$ grown at $\mathrm{Ts}=$ $750{ }^{\circ} \mathrm{C}, 650{ }^{\circ} \mathrm{C}$, and room temperature $\left(\mathrm{pO}_{2}=1.510^{-5} \mathrm{mbar}\right)$. b The sharp drop of the ${ }^{18} \mathrm{O}$ signal near the $\mathrm{SrTiO}_{3}$ surface for the film grown at $\mathrm{TS}=750{ }^{\circ} \mathrm{C}$; taken from [39] with permission deposition took place at relatively low oxygen back ground pressures. In Fig. 4, it was shown that when $\mathrm{SrTiO}_{3}$ was grown on substrates impregnated with ${ }^{18} \mathrm{O}$, SIMS performed after growth detect its presence in the film [39]. At higher temperatures, more ${ }^{18} \mathrm{O}$ from the substrate ended up in the film, presumably by diffusion. Very recently, it was shown by the Wurzburg group using XPS that $\mathrm{d}^{1}-\mathrm{Ti}$ would poorly stabilise on a substrate prone to forming oxygen vacancies [40] and could act as a source for oxygen rendering $\mathrm{d}^{0}-\mathrm{Ti}$ in the film (see Fig. 5). Either the usage of a blocking layer or a more stable substrate material would prevent the oxidation of $\mathrm{Ti}$, leaving more $\mathrm{d}^{1}-\mathrm{Ti}$ in the film, as the authors originally had set out to achieve.

\subsection{Growth Kinetics}

To be able to correlate oxidation to the growth kinetics of complex oxides, we first describe a more indirect experiment that was conducted by Groenen et al. [41]. They grew $\mathrm{SrTiO}_{3}$ thin films on $\mathrm{SrTiO}_{3}$ substrates varying the film thickness. The experiment entailed the comparison of the thickness inferred from both RHEED oscillations (nominal thickness $\mathrm{d}_{\mathrm{est}}$ ) (see right panel of Fig. 6) and XRD Lauefringes (measure thickness $d_{\text {fit }}$ ) (see left panel of Fig. 6). The fact that in XRD a film Bragg peak was at all visible was due to the fact that the films were grown at conditions where
Fig. 5 Ti $2 \mathrm{p}^{3 / 2}$ XPS spectra of LTO films prepared on various substrates. a A strong impact of the substrate choice on the titanium valence is detected. $\mathbf{b}$ Oxygen out-diffusion from the different substrates into the LTO films (see text for details). Taken from [40] with permission

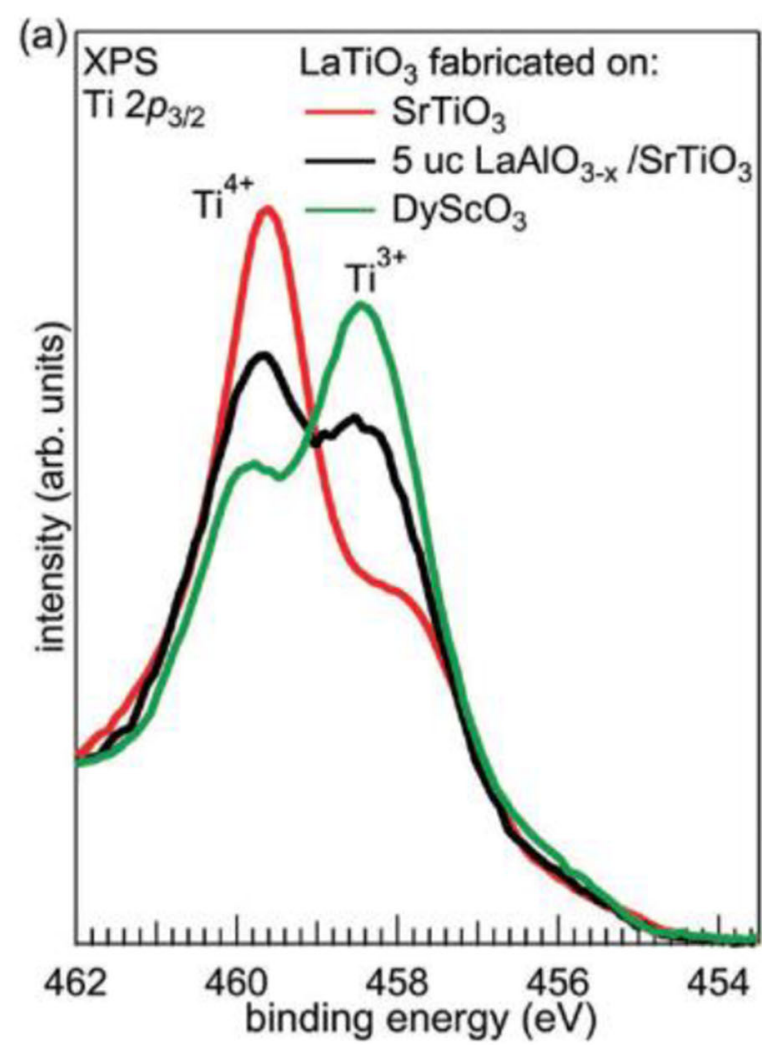

(b)
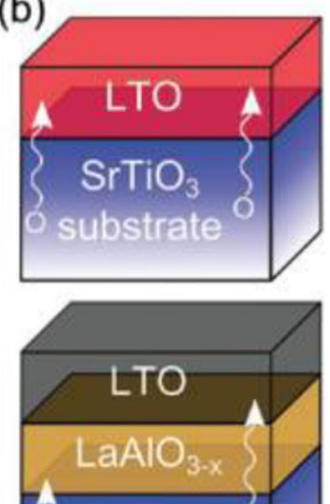

$\mathrm{SrTiO}_{3} \mathrm{O}$ 0 substrate

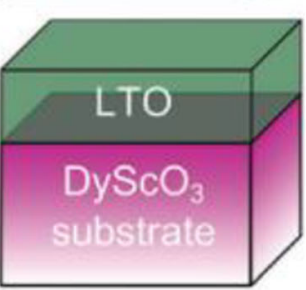


Fig. 6 Left: XRD simulation results shown at three different thicknesses. Samples were grown at 0.01 mbar partial oxygen pressure and a total pressure of 0.08 mbar, aimed thickness derived from initial growth speed is respectively $75 \mathrm{ML}$ (a), $100 \mathrm{ML}$ (b), and 150ML (c). Right: corresponding specular RHEED intensity recorded during deposition. The insets show the AFM topology of the substrates on which the films are grown, taken from [41]
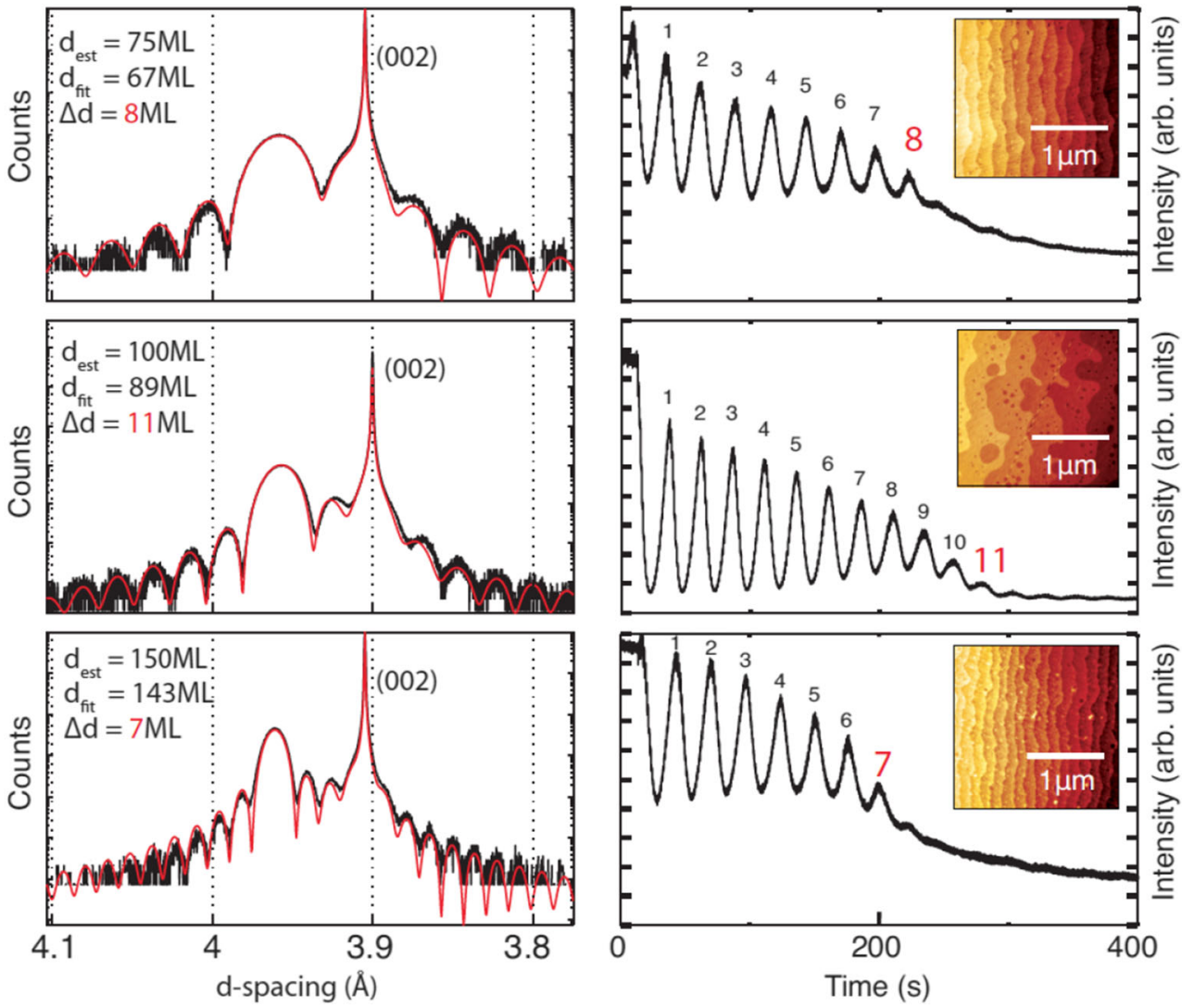

a slight off-stoichiometry was to be expected, giving rise to a slightly different average unit cell size in the thin layer compared to the stoichiometric substrate material. Surprisingly, a thickness difference of about $10 \%$ was measured, which is well outside the range of error when counting RHEED oscillation to determine growth rates. Upon closer inspection of the specular RHEED intensity while depositing, one can clearly see strong oscillations for the first unit cells, with a typical cusp-shape for so-called layer-by-layer growth. However, after a certain thickness $(8$, 11 and 7 for the three thicknesses, respectively, see right panel of Fig. 6), the oscillation ceases and the RHEED pattern becomes that of a more 3D type surface (not shown), indicative of $3 \mathrm{D}$ island growth. The authors reasoned that despite the fact that under the conditions used, an expected lack of oxidised Ti arriving on the surface would lead to offstoichiometry and reduced kinetics, oxygen available from the substrate would diffuse to the surface and help overcome the unfavourable conditions and sustain perfect growth, indistinguishable from the substrate for XRD, but only for a certain thickness. The discrepancy between the expected thickness $\left(\mathrm{d}_{\text {est }}\right)$ and measured thickness $\left(\mathrm{d}_{\mathrm{fit}}\right)$ matched the perfect growth layer for all three samples.

Next, using an advanced laser-induced fluorescence technique, a full compositional spatio-temporal map of the plasma plume became a reality $[42,43]$. These measurements revealed oxidation of the transition metal species in a relatively narrow pressure window, typically from $10^{-2}$ to $10^{-1}$ mbar. With this insight, a relation was made to the type of growth mechanism of thin films and the arrival of certain oxidation states of these species [44]. For $\mathrm{SrTiO}_{3}$, it was concluded that sticking and surface diffusivity leading to perfect layer-by-layer growth and stoichiometric ( $\mathrm{Sr}: \mathrm{Ti}=1: 1$ ) films are connected to the arrival of fully oxidised $\mathrm{Ti}^{4+}$ species. A similar story holds for other compounds, such as $\mathrm{SrVO}_{3}$ ('optimal' species $\mathrm{V}^{4+}$, which means $\mathrm{SrVO}_{3}$ can be over-oxidised at too high pressures) [45] and it is hypothesised that many of the optimal conditions of complex oxide materials as reported in literature can be 'explained' [46]. Even when using non-oxide substrates, for example in the case of oxide growth on $\mathrm{Si}$ with a native oxide present [47], similar considerations are relevant.

\section{Outlook and Conclusions}

We look forward by first bringing a few unusual observations regarding growth kinetics to the attention. The first example is the step flow-like growth seen for perovskite $\mathrm{SrRuO}_{3}$. Rijnders et al. observed that during the deposition of the first few monolayers of this material, a change from layer-by-layer 
Fig. 7 Surface morphologies studied by $1 \times 1 \mu \mathrm{m}$ AFM friction maps of $\mathrm{DyScO}_{3}$ substrates after annealing for a $30 \mathrm{~min}$ and $\mathbf{c} 4 \mathrm{~h}$, indicating the mixed surface termination structures. Images b and $\mathbf{d}$ show corresponding $1 \times$ $1 \mu \mathrm{m}$ STM height maps of the $\mathrm{SrRuO}_{3}$ nanowires after PLD growth on substrates a and c. Line profiles $\mathbf{e}$ and $\mathbf{f}$ give detailed height information, indicating half unit cell steps of the $\mathrm{DyScO}_{3}$ surface before growth (e) and up to 8-nm high nanowires after growth (f). From [49] with permission (a)

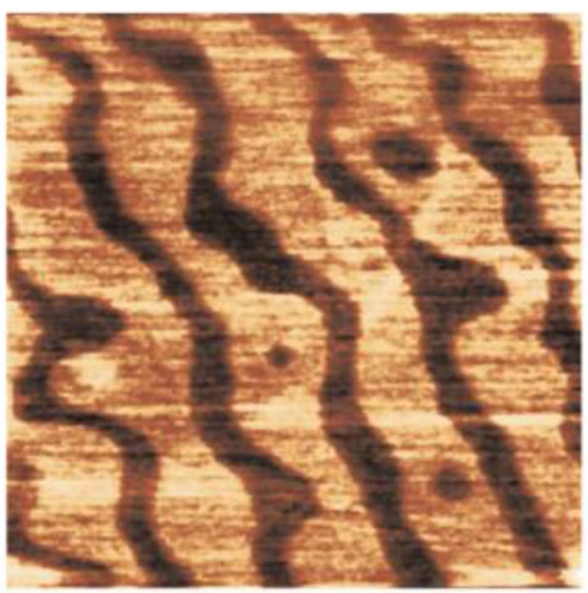

(c)

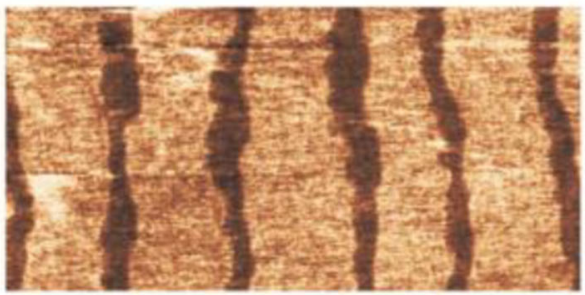

(e)

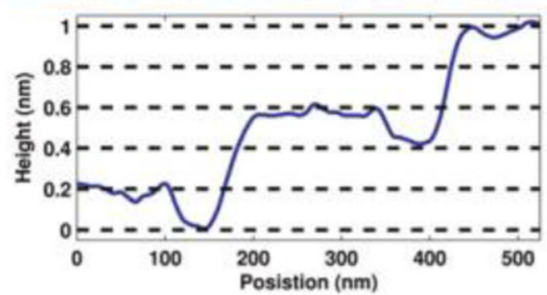

(b)

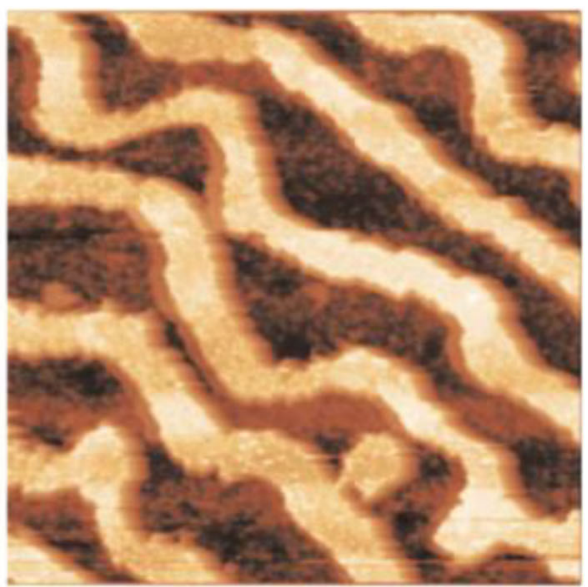

(d)

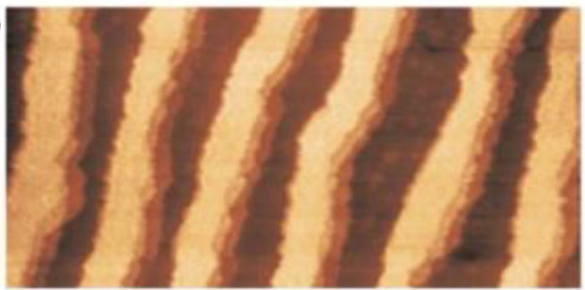

(f)

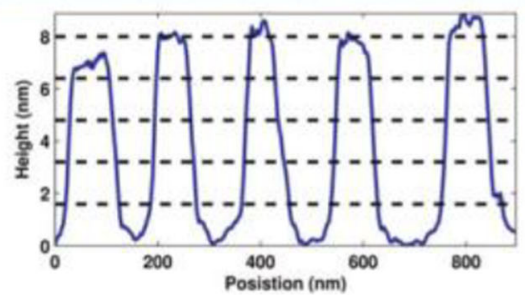

growth to step flow-like growth occurs, which was linked to a switch in the terminating layer at the surface, i.e. from B-side $\mathrm{RuO}_{2}$ to A-side $\mathrm{SrO}$, respectively [48]. Another remarkable observation that was made is the extreme wetting difference of PLD grown $\mathrm{SrRuO}_{3}$ on the two different terminations of an untreated $\mathrm{DyScO}_{3}$ substrate (see Fig. 7). Due to the strong difference in diffusivity, only growth takes place on the Bside terminated terraces [49], leading to crystalline ribbons of film material instead of a uniform layer. Other examples of the sensitivity of the growth kinetics on the terminating layer have been reported, for example $\mathrm{BiFeO}_{3}[50]$. We note here that typically these materials are grown under 'high pressure' conditions $\left(\mathrm{pO}_{2}>0.1 \mathrm{mbar}\right)$ resulting in oxidised cationic species arriving on the surface. To our knowledge, this sensitivity to termination is not observed in the low-pressure regime and therefore, we assume that the combination of termination and oxidation state of the arriving species are intimately responsible for the observed surface kinetics.

We conclude that the sources of oxygen in PLD complex oxide thin film growth have become clear and should be considered with every new film-substrate combination or heterostructure while looking for the optimal growth conditions. In our opinion, it is necessary to develop experiments and new kinetic models for the growth of complex oxides. The observations related to surface termination and kinetics hint to the microscopic and complex surface diffusion mechanisms that deserve our attention in the future.

Open Access This article is distributed under the terms of the Creative Commons Attribution 4.0 International License (http:// creativecommons.org/licenses/by/4.0/), which permits unrestricted use, distribution, and reproduction in any medium, provided you give appropriate credit to the original author(s) and the source, provide a link to the Creative Commons license, and indicate if changes were made.

\section{References}

1. Dijkkamp, D., et al.: Preparation of Y-Ba-Cu oxide superconductor thin films using pulsed laser evaporation from high Tcbulk material. Appl. Phys. Lett. 51, 619-621 (1987)

2. Wu, M.K., et al.: Superconductivity at $93 \mathrm{~K}$ in a new mixed-phase Y-Ba-Cu-O compound system at ambient pressure. Phys. Rev. Lett. 58, 908-910 (1987)

3. Chrisey, D. B. \& Hubler, G. K. Pulsed Laser Deposition of Thin Films. (1994) 
4. Norton, M.G., Carter, C.B.: On the optimization of the laser ablation process for the deposition of $\mathrm{YBa} 2 \mathrm{Cu} 3 \mathrm{O} 7$-delta thin-films. Physica C: Superconductivity. 172, 47-56 (1990)

5. Weimer, W.A.: Plasma emission from laser ablation of the hightemperature superconductor $\mathrm{YBa} 2 \mathrm{Cu} 3 \mathrm{O}$ 7. Appl. Phys. Lett. 52, 2171-2173 (1988)

6. Dam, B., Rector, J., Johansson, J., Huijbregtse, J., Groot, D.G.D.: Mechanism of incongruent ablation of SrTiO3. J. Appl. Phys. 3386(6), 3386-3389 (1998)

7. Dam, et al.: Stoichiometric transfer of complex oxides by pulsed laser deposition. Appl. Surf. Sci. 96-8, 679-684 (1996)

8. Ohnishi, T., Lippmaa, M., Yamamoto, T., Meguro, S., Koinuma, H.: Improved stoichiometry and misfit control in perovskite thin film formation at a critical fluence by pulsed laser deposition. Appl. Phys. Lett. 87(24), 1-3 (2005)

9. T. Ohnishi, K. Shibuya, T. Yamamoto, and M. Lippmaa, "Defects and transport in complex oxide thin films," J. Appl. Phys., vol. 103, no. 10, pp. 0-6, 2008, 103703

10. Geohegan, D.B.: Physics and diagnostics of laser ablation plume propagation for high-TC superconductor film growth. Thin Solid Films. 220(1-2), 138-145 (1992)

11. Sambri, A., Amoruso, S., Wang, X., Granozio, F.M., Bruzzese, R.: Plume propagation dynamics of complex oxides in oxygen. J. Appl. Phys. 104(5), 053304 (2008)

12. Geohegan, D.B., Puretzky, A.a.: Laser ablation plume thermalization dynamics in back-ground gases: combined imaging, optical absorption and emission spectroscopy, and ion probe measurements. Appl. Surf. Sci. 96-98, 131-138 (1996)

13. Amoruso, S., Aruta, C., Bruzzese, R., Maccariello, D., Maritato, L., Granozio, F.M., Orgiani, P., Scotti di Uccio, U., Wang, X.: Optimization of $\mathrm{La} 0.7 \mathrm{Ba} 0.3 \mathrm{MnO} 3-\delta$ complex oxide laser ablation conditions by plume imaging and optical emission spectroscopy. J. Appl. Phys. 108(4), 043302 (2010)

14. Aruta, C., Amoruso, S., Bruzzese, R., Wang, X., Maccariello, D., Miletto Granozio, F., Scotti di Uccio, U.: Pulsed laser deposition of SrTiO3/LaGaO3 and SrTiO3/LaAO3: plasma plume effects. Appl. Phys. Lett. 97(25), 252105 (2010)

15. Xu, C., Wicklein, S., Sambri, A., Amoruso, S., Moors, M., Dittmann, R.: Impact of the interplay between nonstoichiometry and kinetic energy of the plume species on the growth mode of SrTiO3 thin films. J. Phys. D. Appl. Phys. 47(3), 034009 (2014)

16. Ojeda-G-P, A., Schneider, C.W., Lippert, T., Wokaun, A.: Pressure and temperature dependence of the laser-induced plasma plume dynamics. J. Appl. Phys. 120(22), 225301 (2016)

17. Strikovski, M., Miller, J.H.: Pulsed laser deposition of oxides: why the optimum rate is about $1 \AA$ per pulse. Appl. Phys. Lett. 73(12), 1733 (1998)

18. S. Wicklein, a. Sambri, S. Amoruso, X. Wang, R. Bruzzese, A. Koehl, and R. Dittmann, "Pulsed laser ablation of complex oxides: the role of congruent ablation and preferential scattering for the film stoichiometry," Appl. Phys. Lett., vol. 101, no. 13, p. 131601, 2012

19. Chen, J., Döbeli, M., Stender, D., Conder, K., Wokaun, A., Schneider, C.W., Lippert, T.: Plasma interactions determine the composition in pulsed laser deposited thin films. Appl. Phys. Lett. 105(11), (2014)

20. Amoruso, S., Toftmann, B., Schou, J.: Thermalization of a UV laser ablation plume in a background gas: From a directed to a diffusion like flow. Physical Review E. 69(5), 056403 (2004)

21. Amoruso, S., Aruta, C., Aurino, P., Bruzzese, R., Wang, X., Granozio, F.M., Scotti di Uccio, U.: Oxygen background gas influence on pulsed laser deposition process of $\mathrm{LaAlO} 3$ and $\mathrm{LaGaO} 3$. Appl. Surf. Sci. 258, 9116-9122 (2012)

22. Amoruso, S., Aruta, C., Bruzzese, R., Wang, X., Scotti Di Uccio, U.: Substrate heating influence on the deposition rate of oxides during pulsed laser deposition in ambient gas. Appl. Phys. Lett. 98(2011), 9-12 (2011)

23. Sambri, A., Radovic, M., Wang, X., Amoruso, S., Granozio, F.M., Bruzzese, R.: Substrate heating effects on the propagation dynamics of laser produced plume during pulsed laser deposition of oxides. Appl. Surf. Sci. 254(4), 790-793 (2007)

24. A. Sambri, S. Amoruso, X. Wang, M. Radovic', F. Miletto Granozio, and R. Bruzzese, "Substrate heating influence on plume propagation during pulsed laser deposition of complex oxides," Appl. Phys. Lett., vol. 91, no. 15, p. 151501, 2007

25. Eason, R.: Pulsed Laser Deposition of Thin Films. Wiley (2007)

26. J. Schou, S. Amoruso, and J. G. Lunney, "Laser Ablation and Its Applications," pp. 67-95, 2007

27. Willmott, P.R., Huber, J.R.: Pulsed laser vaporization and deposition. Rev. Mod. Phys. 72(1), 315-328 (2000)

28. Rijnders in Eason ref. 25

29. Koster et al in Koster, G. \& Rijnders, G. In Situ Characterization of Thin Film Growth. 1-282 (2011)

30. Christen, H.M., Eres, G.: Recent advances in pulsed-laser deposition of complex oxides. J Phys-Condens Mat. 20, 264005-264017 (2008)

31. Fröhlingsdorf, J., Zander, W., Stritzker, B.: Direct preparation of high-Tc-superconducting films by laser ablation. Solid State Commun. 67, 965-966 (1988)

32. Roas, B., Schultz, L., Endres, G.: Epitaxial growth of $\mathrm{YBa} 2 \mathrm{Cu} 3 \mathrm{O}$ 7- xthin films by a laser evaporation process. Appl. Phys. Lett. 53, 1557-1559 (1988)

33. Hammond, R.H., BORMANN, R.: Correlation between the in situ growth-conditions of Ybco thin-films and the thermodynamic stability-criteria. Physica C: Superconductivity. 162, 703-704 (1989)

34. Ingle, N., Hammond, R.H., Beasley, M.R., Blank, D.: The generation and detection of high flux atomic oxygen for physical vapor deposition thin film growth. Appl. Phys. Lett. 75, 4162-4164 (1999)

35. Geohegan, D.B., Puretzky, A.A., Duscher, G., Pennycook, S.J.: Time-resolved imaging of gas phase nanoparticle synthesis by laser ablation. Appl. Phys. Lett. 72, 2987-2989 (1998)

36. Chen, J., et al.: Tracing the origin of oxygen for $\mathrm{La} 0.6 \mathrm{Sr} 0.4 \mathrm{MnO} 3$ thin film growth by pulsed laser deposition. J. Phys. D-Appl. Phys. 49, 045201 (2016)

37. García López, J., Blank, D.H.A., Rogalla, H., Siejka, J.: Role of the oxygen plasma during in situ growth of $\mathrm{YBa} 2 \mathrm{Cu} 3 \mathrm{O} 6+\mathrm{x}$ thin films by pulsed laser deposition. Physica C: Superconductivity. 307, 298-306 (1998)

38. López, J.G., Blank, D., Rogalla, H., Siejka, J.: Oxygenation mechanism of $\mathrm{YBa} 2 \mathrm{Cu} 3 \mathrm{O} 6+\mathrm{x}$ thin films during growth by pulsed laser deposition. Appl. Supercond. 1997. 1(2), 113116 (1997)

39. Schneider, C.W., et al.: The origin of oxygen in oxide thin films: role of the substrate. Appl. Phys. Lett. 97, 192107-192104 (2010)

40. Scheiderer, P., et al.: Tailoring materials for Mottronics: excess oxygen doping of a prototypical Mott insulator. Adv. Mater. 30, 1706708-1706707 (2018)

41. Groenen, R., et al.: Research update: stoichiometry controlled oxide thin film growth by pulsed laser deposition. APL Mater. 3, (2015)

42. Orsel, K.: Analysis of transient plasmas for pulsed laser deposition using spatiotemporally resolved laser-induced fluorescence. spectroscopy. (2016)

43. Orsel, K., Groenen, R., Bastiaens, B., Koster, G., Rijnders, G., Boller, K.: Laser-induced fluorescence analysis of plasmas for stoichiometric growth of $\mathrm{YBiO} 3$ films with pulsed laser deposition. APL Materials. 126102, 1-7 (2016)

44. Orsel, K., Groenen, R., Bastiaens, B., Koster, G., Rijnders, G., Boller, K.: Influence of the oxidation state of SrTiO3 plasmas for stoichiometric growth of pulsed laser deposition films 
identified by laser induced fluorescence. APL Materials. 106103(3), 0-8 (2015)

45. Wang, J., Rijnders, G., Koster, G.: Complex plume stoichiometry during pulsed laser deposition of $\mathrm{SrVO} 3$ at low oxygen pressures. Appl. Phys. Lett. 113, 223103 (2018)

46. E.g., Boschker, H, et al.: Optimized fabrication of high-quality $\mathrm{La} 0.67 \mathrm{Sr} 0.33 \mathrm{MnO} 3$ thin films considering all essential characteristics. J. Phys. D-Appl. Phys. 44, 205001-205010 (2011)

47. Dubbink, D., Koster, G., Rijnders, G.: Growth mechanism of epitaxial YSZ on Si by pulsed laser deposition. Nat. Publ. Group. 8(5774), (2018)
48. Rijnders, G., Blank, D., Choi, J., Eom, C.: Enhanced surface diffusion through termination conversion during epitaxial $\mathrm{SrRuO} 3$ growth. Appl. Phys. Lett. 84, 505-507 (2004)

49. Kuiper, B., et al.: Self-organization of $\mathrm{SrRuO} 3$ nanowires on ordered oxide surface terminations. MRC. 1, 17-21 (2011)

50. Solmaz, A., et al.: Domain selectivity in $\mathrm{BiFeO} 3$ thin films by modified substrate termination. Adv. Funct. Mater. 26, 28822889 (2016)

Publisher's Note Springer Nature remains neutral with regard to jurisdictional claims in published maps and institutional affiliations. 